\title{
OPTICS AND MATERIALS RESEARCH FOR CONTROLLED RADIANT ENERGY TRANSFER IN BUILDINGS
}

\author{
DOE/GO/10096-T)
}

Final Technical Report

for period ending June 1996

Ronald B. Goldner, P.I.

Electro-Optics Technology Center

Tufts University

4 Colby Street

Medford, MA 02155

Date Published - July 1996

DISTAIBUTION OF THIS DOCUMENT IS UNLIMTED

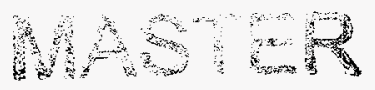

Prepared for the U.S. Department of Energy

DE-FG36GO-10096 \& DE-FG03-85SF15927

(DE-FG36-95 1010096$)$ 


\section{DISCLAIMER}

This report was prepared as an account of work sponsored by an agency of the United States Government. Neither the United States Government nor any agency thereof, nor any of their employees, makes any warranty, express or implied, or assumes any legal liability or responsibility for the accuracy, completeness, or usefulness of any information, apparatus, product, or process disclosed, or represents that its use would not infringe privately owned rights. Reference herein to any specific commercial product, process, or service by trade name, trademark, manufacturer, or otherwise does not necessarily constitute or imply its endorsement, recommendation, or favoring by the United States Government or any agency thereof. The views and opinions of authors expressed herein do not necessarily state or reflect those of the United States Government or any agency thereof. 


\section{DISCLAIMER}

Portions of this document may be illegible electronic image products. Images are produced from the best available original document. 
Optics and Materials Research for Controlled Radiant Energy Transfer in Buildings

\section{Table of Contents}

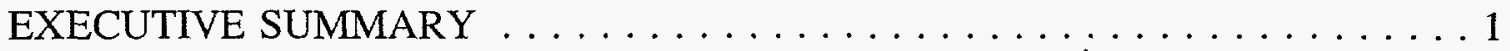

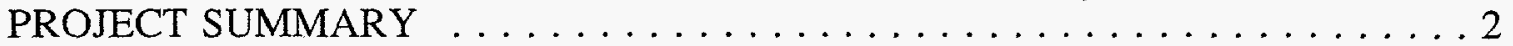

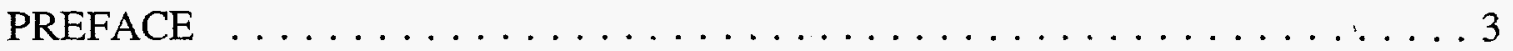

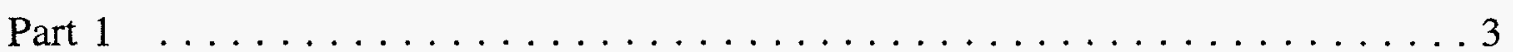

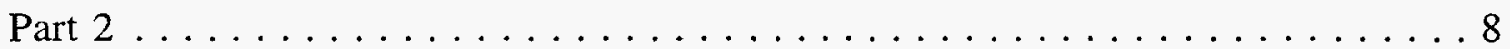

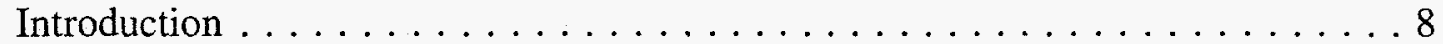

Requirements of Building and Vehicle EC Windows $\ldots \ldots \ldots \ldots \ldots$

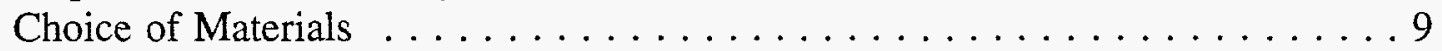

Properties of $\mathrm{pc}^{-\mathrm{WO}_{3} \text { and } \mathrm{LiCoO}_{2} \ldots \ldots \ldots \ldots \ldots \ldots \ldots \ldots \ldots \ldots \ldots \ldots}$

Table 1 - Summary of Recommended Materials

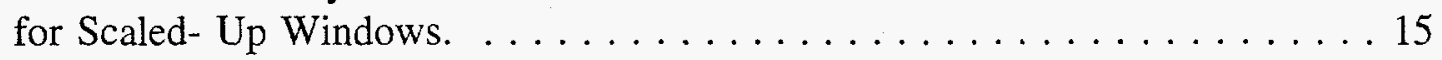

References .......................... 18

Appendix I

Some significant accomplishments obtained at Tufts EOTC $\ldots \ldots \ldots \ldots 19$ Appendix II

Published papers related to DOE-sponsored electrochromic

windows research at Tufts University $\ldots \ldots \ldots \ldots \ldots \ldots \ldots \ldots \ldots$

Appendix III

Personnel who have worked on project $\ldots \ldots \ldots \ldots \ldots \ldots \ldots \ldots 22$ Reprints:

Solid State Ionics 70/71, 613-618 (1994).

J. Vac. Sci. Technol. A13(3), May/Jun 1995.

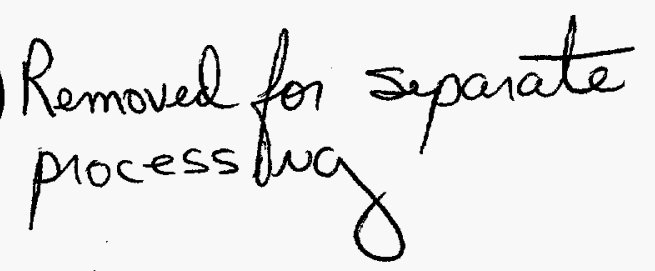




\title{
FINAL TECHNICAL REPORT
}

\author{
"Optics and Materials Research for Controlled Radiant Energy Transfer in Buildings" \\ Dept. of Energy Grants DE-FG36-95GO10096 \& DE-FG03-85SF15927 \\ Ronald B. Goldner, P.I. \\ Tufts University, 4 Colby St., Medford, MA 02155
}

\section{EXECUTIVE SUMMARY}

1. The over-riding issue for building and vehicle electrochromic windows (ECW's) is durability, especially to solar radiation and to relatively high voltages.

Generally, for materials with weak bonds, (e.g., organic electrolytes), solar radiation causes bond breaking which results in chemical, mechanical, and electrical degradation as well as optical damage such as discoloration and/or optical scattering and cloudiness. Heating due to optical absorption of solar radiation can also cause strain-induced mechanical failures - at the very least failures of the coatings, but of a more serious nature is fracturing of the glass glazing itself. Unwanted irreversible chemical reactions (oxidations and/or reductions) can occur also in weakly bonded materials when they are exposed to voltages in excess of their oxidation or reduction potentials.

Therefore, to attain durability, one should use: (a) spectrally-selective reflectivity modulation (to minimize optical absorption and still obtain the desired spectrally selective transmissivity properties); (b) $\mathrm{Li}^{+}$instead of the proton $\left(\mathrm{H}^{+}\right)$as the charge-compensating ion (since all known room temperature proton conducting electrolytes are essentially water, which is difficult to seal in, and for which water electrolysis occurs at less than $2 \mathrm{~V}$ ); and (c) an inorganic (instead of an organic) electrolyte.

To obtain spectrally-selective reflectivity modulation, one should use: (a) structurally and compositionally ordered $\mathrm{pc}^{-\mathrm{WO}_{3}}=\mathrm{EC}_{1}$ since it appears to be unique among all known and predicted EC materials as regards its inherent ability to provide significant reflectivity modulation; (b) structurally and compositionally ordered $\mathrm{LiCoO}_{2}=\mathrm{EC}_{2}$ [or possibly mixed $\mathrm{LiMO}_{2}$ films, $(\mathrm{M}=$ one of the transition metal elements - e.g., $\mathrm{Co}, \mathrm{Cr}, \mathrm{Ni}$, since its band structure seems to be close to ideal for obtaining the optical properties of a complementary p-type $\mathrm{EC}$ material to (n-type) $\mathrm{WO}_{3}$.

2. The principal manufacturing issue is the attainment of high throughput at low cost, and the crux of the matter is to devise a relatively high rate deposition process for the electrolyte layer that provides high yield [i.e., window cells that are free of electronic shorts or severe electronic "leaks", which is operationally equivalent to cells having relatively long retention times for their optical state (usually the colored state)]. This has not yet been demonstrated for samples larger than laboratory-scale $\mathrm{Li}^{+}$window cells $\left(<20 \mathrm{~cm}^{2}\right)$.

3. Laboratory-scale ECW cells $\left(\approx 2 \mathrm{~cm}^{2}\right)$ have been routinely deposited at Tufts with high yields using if sputtering and thermal evaporation. These cells are durable $(>20,000$ cycles at $>60^{\circ} \mathrm{C}$ and in a normal laboratory environment, where the relative humidity was usually $>50 \%$ 
and sometimes approached $60 \%$, with no measurable degradation). These cells employed an electrolyte of amorphous lithium niobate, (LNO, of thickness $\approx 450 \mathrm{~nm}$ ) with electron barriers on either side of it, together with $\mathrm{TC}_{1}=\operatorname{ITO}(150 \mathrm{~nm}), \mathrm{EC}_{1}=\mathrm{pc}^{-\mathrm{WO}_{3}}(120 \mathrm{~nm})$, a lithium ion blocking layer of n-type $\mathrm{SiC}(<20 \mathrm{~nm}), \mathrm{EC}_{2}=\mathrm{LiCoO}_{2}(40 \mathrm{~nm}), \mathrm{TC}_{2}=\mathrm{In}_{2} \mathrm{O}_{3}(100 \mathrm{~nm})$, and a sealing layer of $\mathrm{Si}_{3} \mathrm{~N}_{4}(150 \mathrm{~nm})$. Their total thicknesses are approximately 1 to $1.25 \mu \mathrm{m}$.

4. Probably all the layers can be deposited relatively rapidly on to an unheated substrate by processes developed or being developed at Tufts. However, it is important to better understand the materials science aspects of promising and/or novel deposition processes prior to technology transfer. Otherwise, much wasted resources will be expended carrying out essentially purely empirical studies or, worse, industry will react very negatively to electrochromic windows, which are devices that require the same type of understanding as what was and is still required by the semiconductor industry. Unless the deposition parameters/nanostructure/thermomechanical properties relationships are reasonably well understood, the consequences can be dire for ECW technology, no less the DOE ECW program. This is because, in the present economic climate, industry has been very reluctant to invest in such basic research, but without doing so, costly errors are very likely to be made. Since it is government's rightful role to invest in the discovery of new knowledge and its dissemination (largely via the education of its citizens), it is strongly recommended that public monies be so invested - i.e., by funding a research program of this nature at one or more universities. An example of the value of such research is summarized in Appendix I which lists some of the major accomplishments that resulted from the DOE-sponsored ECW research program at Tufts University. Also, as listed in Appendix II, this information has been made publicly available via more than three dozen publications (in addition to a like number of invited public technical lectures.

\section{PROJECT SUMMARY}

The primary objective of this project was to perform the optics and materials research necessary to identify and solve the technical problems associated with fabricating durable, variable reflectivity electrochromic windows for energy efficient buildings and vehicles.

The research performed at the Tufts Electro-Optics Technology Center (EOTC) has identified and solved nearly all the significant problems, as discussed below in this final technical report. There still remains, however, one important problem to be solved - i.e., to better understand the science of deposition processes and thereby develop and optimize one or more production-worthy deposition processes that could be used for the practical production of affordable, variable reflectivity electrochromic windows.

Therefore, it is recommended that such studies be carried out with the goals of: (i) determining the probable practical limits of performance; and, very importantly, (ii) to develop and optimize deposition processes that could be used for the practical production of affordable electrochromic windows. 


\section{PREFACE}

This report is divided into two parts. The first part presents a series of general questions and answers related to the design of electrochromic windows for buildings and vehicles based upon modeling studies carried out at Tufts. The second part is focused on recommended choices for materials and processes to produce practical windows, based on experiments and measurements done on thin film electrochromic windows that have been fabricated at Tufts. The technology developed at Tufts has been developed specifically to allow one to produce, by production-worthy processes, robust, energy-efficient windows for optimizing the radiation transfer in buildings and vehicles.

At the end of the second part are, respectively, a list of major accomplishments at Tufts and a list of papers that have been published on the research supported under this grant. Accompanying this report are selected reprints of some of the published articles that describe in further detail some of the DOE-sponsored electrochromic windows research at Tufts.

\section{PART 1}

Q1 The principal issue for any electrochromic device is to determine what is the spectral range over which the optical properties will be modulated and what should be the degree of modulation? Therefore, we raise this question in regard to designing and manufacturing windows for buildings and vehicles which will minimize the energy for heating, cooling, and lighting (or viewing in the case of vehicle windows).

A1 Consider the thermal, or Planck, radiation wavelength distribution characteristics of a unit emissivity body at a temperature $T(\mathrm{~K})$. As is well known [1,2] the peak in the distribution occurs at a wavelength, $\lambda_{\text {peak }}(\mu \mathrm{m}) \approx 3000 / \mathrm{T}(\mathrm{K})$. A universal Planck radiation curve is shown in Figure 1, which was taken from Reference [2]. For example, the sun can be considered to be at a temperature of $\approx 6000 \mathrm{~K}$; therefore, its radiation peaks at a wavelength of approximately $0.5 \mu \mathrm{m}$ (yellow-green). On the other hand the radiation from the walls of a room at $300 \mathrm{~K}\left(27^{\circ} \mathrm{C}\right)$ peaks at a wavelength of approximately $10 \mu \mathrm{m}$ (thermal infrared).

Now consider the following situations: 


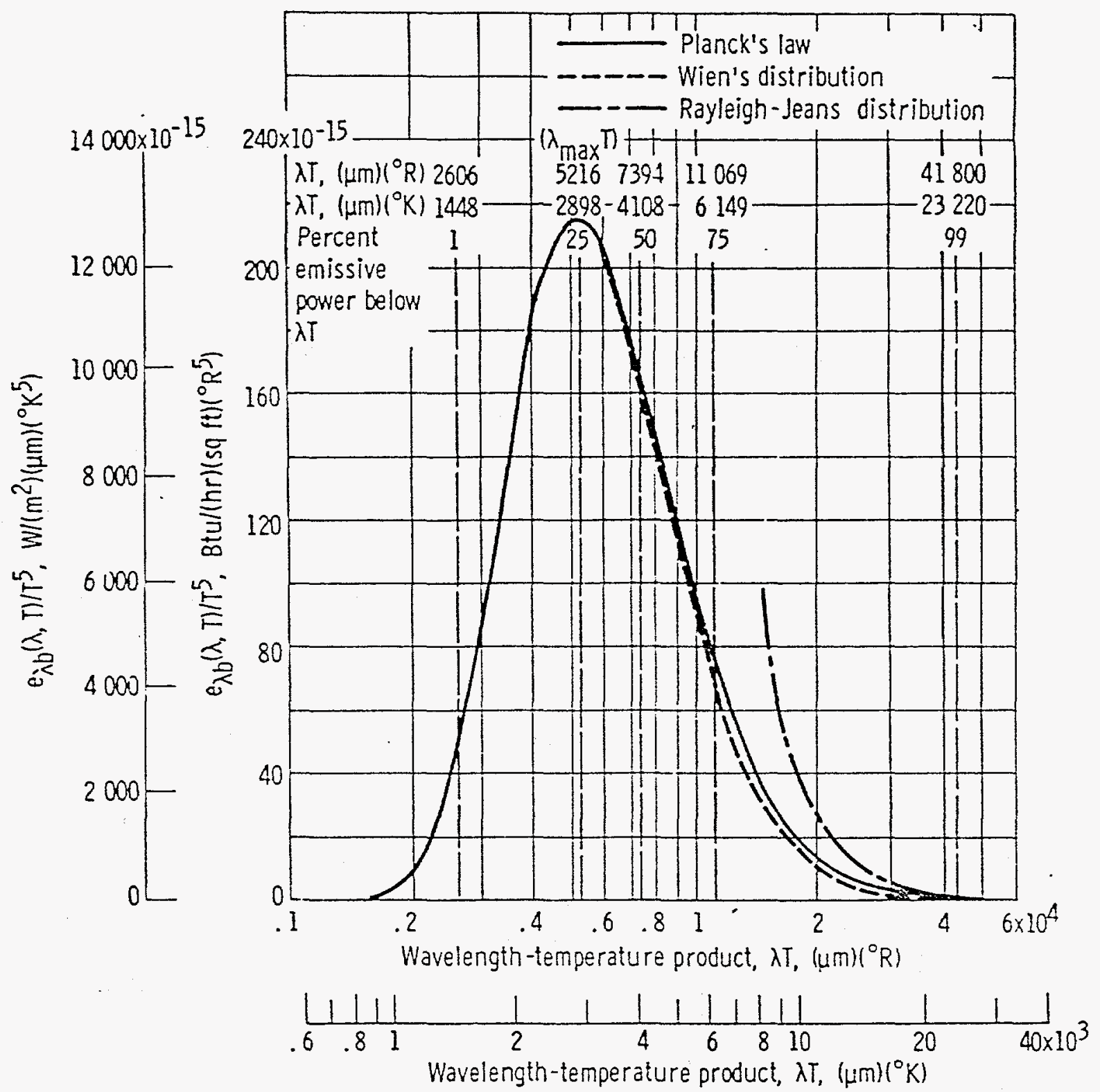

Fig. 1 -Spectral distribution of blackbody hemispherical emissive power. 
Situation (i) - In this situation, we have a cold, but sunny, winter day. To maximize solar gain, (increase in energy from the sun that is used by the building or vehicle), and therefore reduce the heating load, the window should transmit the entire solar spectrum (except for ultraviolet photons of wavelength less than $\approx 0.4 \mu \mathrm{m}$ ), but reflect back into the interior of either a building or a vehicle the thermal infrared radiation being emitted by all the objects, including people, within the structure.

Situation (ii) - In this situation, consider a building on a cold winter night or a parked vehicle on a hot summer sunny day. For both the building and the vehicle it is desirable to have all radiation incident upon the window be back-reflected. In the building window case we wish

to retain (reflect back) all the radiation emitted within for two reasons: (a) to conserve heating energy; and (b) for privacy or security reasons - e.g., avoid neighbors from seeing within). In the vehicle case we wish to reflect away all incident solar radiation for two similar reasons: (a) to conserve cooling energy by preventing solar energy gain; and (b) also for privacy (security) reasons - e.g., to prevent persons from seeing what is being stored in the vehicle.

Situation (iii) - In this situation, consider a building or a moving vehicle on a hot summer day. In both cases one wishes to reflect away all solar radiation except for the visible spectrum to conserve daylighting energy in the building case and to allow viewing in the vehicle case, yet still minimize the cooling energy load.

Situation (iv) - In this case, consider a hot, cloudless, summer night for both the building and vehicle. We wish to utilize radiation cooling by transmitting (through a roof window) all thermal radiation, but especially in the 8 to $12 \mu \mathrm{m}$ wavelength region where there is a transmission "window" in a relatively dry atmosphere. (This is generally difficult to achieve because of the poor infrared transmissivity of most structurally acceptable roofing materials.)

An important issue is that reflectivity modulation has been proposed, rather than absorptivity modulation. This was intentional for several reasons: (a) reflectivity modulation provides spectrally selective transmissivity modulation (or adjustable band-pass filtering), compared to spectrally fixed, nearly neutral density filtering by absorption modulation; (b) optical absorption is dissipative, generates heat, and can lead to damaging, thermally-caused strain (please note a recent newspaper article related to this issue, a reprint of which is in the Appendix A); (c) absorptivity modulation is less thermally efficient since absorbed radiation results in a reradiation at longer wavelengths, and the re-radiation emits equally in forward and backward directions; and (d) thinner films can be used for reflectivity modulation, leading to lower manufacturing costs, more durable (e.g., lower stressed) films, more rapid switching, and less energy to switch states. For building windows, the durability issue translates into greater than 25 years of active use.

Q2 How can one attain spectrally-selective reflectivity modulation?

A2 High reflectivity occurs when there is constructive interference from a collection 
of electrons.

When the electrons are in localized, or bound states (in insulators, or dielectrics), a periodic (layered), inhomogeneous structure can be utilized (e.g., multiple interference optical filters which employ alternating high and low refractive index optically thin layers). To modulate the spectral reflectivity of such filters would require modulating the optical thicknesses of the interference layers. However, the practical realization of such an active filter, especially for a wide spectral range, has not yet been demonstrated.

When the collection of electrons are delocalized or relatively free, (e.g., a "plasma" in metals and semiconductors), the reflectivity is high below the screened plasma resonance frequency, $\omega_{p}^{*}=\sqrt{ }\left(\left[n_{e}\right] q^{2}\right) /\left(m^{*} \varepsilon_{o} \varepsilon_{b}\right)$, where $\left[n_{e}\right]=$ density of free electrons (or holes), $q$ $=$ their charge, $\mathrm{m}^{*}=$ their effective mass, $\varepsilon_{\mathrm{o}}=$ vacuum permittivity $\left(8.85 \times 10^{-12} \mathrm{~F} / \mathrm{m}\right)$, and $\varepsilon_{\mathrm{b}}=$ relative permittivity associated with the localized or bound electrons, (and $\varepsilon_{\mathrm{b}}$ can be frequency dependent) ; and the reflectivity is low below the screened plasma resonance frequency, $\omega_{\mathrm{p}}{ }^{*}$. (The transition width, in photon energy, between low and high reflectivity, and the "step" height of the step-like reflectivity function (of photon energy), are both functions of the free electron scattering or their "damping" after being excited by an incident photon.) This is illustrated in Fig. 2 which are computer generated plots of the photon energy dependence of the reflectivity for an idealized Drude metal $[1,2]$. The plasma energy, $E_{p}=(h / 2 \pi) \omega_{p}, h=$ Planck's constant, and $\omega_{\mathrm{p}}$ = plasma frequency $=\left(\varepsilon_{\mathrm{b}}\right)^{0.5} \omega_{\mathrm{p}}{ }^{*}$. The damping, or loss, energy parameter, $\mathrm{E}_{\Gamma}=\mathrm{a}$ measure of the free electron scattering at optical frequencies. Note that there is a simple "rigid" translation, in energy, of the reflectivity "step", as the plasma energy is changed but, since energy, or frequency, is reciprocally related to wavelength, the "step-like" shape alters when the reflectivity is plotted against wavelength. That is, as $E_{p}$ changes, the reflectivity vs wavelength curve does not rigidly translate in wavelength.

It follows that one can obtain a spectrally selective reflectivity function of the type needed by modulating the density of free electrons or holes. This cannot be achieved with ordinary metals or semiconductors, because of charge neutrality requirements. However, with electrochromic materials, which are mixed electron-ion conductors, this can be done by reversible double insertion or extraction of electrons and charge-compensating ions.

Q3 How can one attain spectrally selective reflectivity modulation with an electrochromic (EC) window, and what are appropriate EC materials for building and vehicle EC windows?

A3 As mentioned at the end of $\mathrm{A} 2$, it was decided that the overriding design principle, variable optical filtering by spectrally-selective reflectivity modulation, probably could be attained by using EC materials. Also, it was decided that such reflectivity modulation could be achieved most practically by the use of the "rocking-chair" EC window (ECW) of Fig. 3. This is basically a five-layer structure, in which the inner three layers are comprised of two mixed electron/ionconducting $\mathrm{EC}$ electrodes $\left(\mathrm{EC}_{1}\right.$ and $\left.\mathrm{EC}_{2}\right)$, that are separated by an ion-conducting (or solid electrolyte) layer, IC. These three layers are sandwiched between two electronically-conducting transparent conductors, $\mathrm{TC}_{1}$ and $\mathrm{TC}_{2}$.

The Tufts ECW employs two complementary Type $2 \mathrm{EC}$ materials, $\mathrm{WO}_{3}$ and $\mathrm{LiCoO}_{2}$. [ $\mathrm{A}$ Type $2 \mathrm{EC}$ material is one for which the optical properties are reversibly altered in the manner 


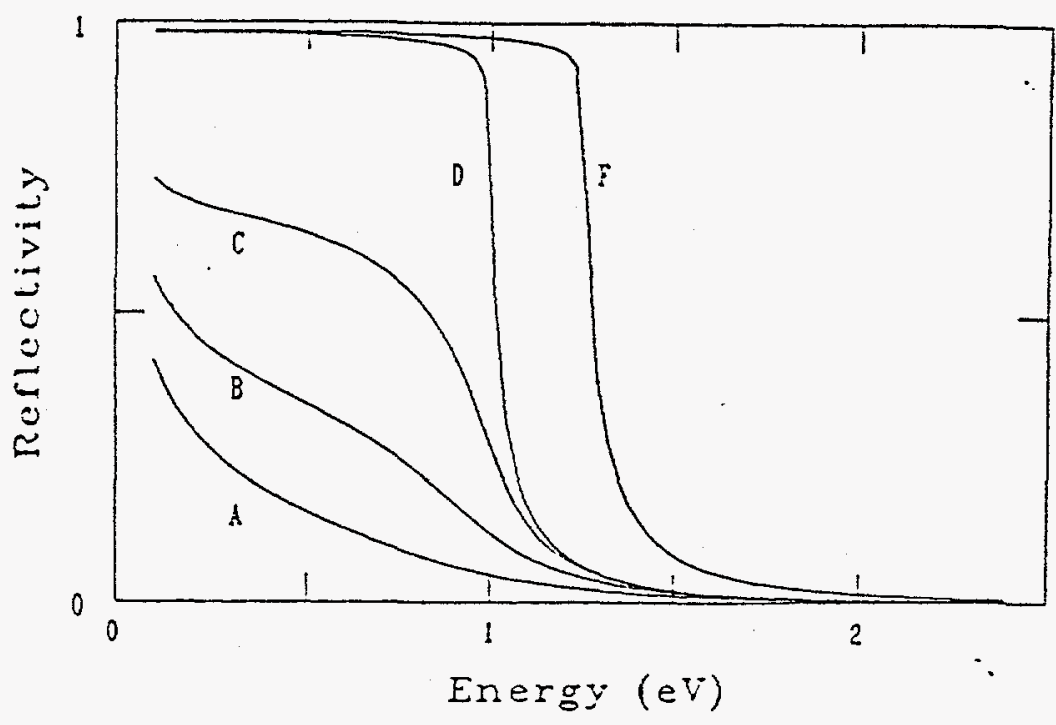

Fig. 2 Reflectivity as a function of energy for various values of the Drude model parameters. Curves $A$ through $D$ all have $E_{p}=1.0 \mathrm{eV}$, with $E_{T}=1.0,0.5,0.2$ and 0.01 $\mathrm{eV}$, respectively. Curve $F$ has $E_{p}=1.25 \mathrm{eV}$ with $E_{T}=0.01 \mathrm{eV}$. The value of $\varepsilon_{\mathrm{b}}$ was taken as unity for all curves.

\begin{tabular}{|c|}
\hline $\mathrm{TC}_{2}$ Layer \\
\hline $\mathrm{EC}_{2}$ Layer \\
\hline IC Layer \\
\hline $\mathrm{EC}_{1}$ Layer \\
\hline $\mathrm{TC}_{1}$ Layer \\
\hline \\
Substrate \\
\hline
\end{tabular}

Fig.: 3 Thin film electrochromic $(E C)$ window. $T C=$ transparent eicctron conductor, $\mathrm{IC}=$ ion conductor. 
previously mentioned (double insertion or extraction of electrons or holes and chargecompensating ions which leads, principally, to a change of occupation of the electron states). In a Type $1 \mathrm{EC}$ material, an applied electric field can lead, principally, to a change in the electron states, and thereby affect primarily the optical absorption,rather than the reflectivity.] The choice of two complementary Type 2 EC materials allows for synchronous modulation of the screened plasma frequencies of the two EC layers - i.e., the two plasma frequencies synchronously change in the same direction, since when electrons are extracted from (or holes are injected into) one EC layer, the electrons are injected into the other EC layer. Thus, to reversibly switch, or modulate, between any two reflectivity states (e.g., between the extreme optical states of high and low reflectivity) over the solar spectrum, one would "rock" back and forth between the two EC layers, electrons via an external circuit, and charge-compensating ions (e.g., $\mathrm{Li}^{+}$) via the IC layer. The notion of a "rocking-chair" is associated with the electron and ion concentrations, and therefore the Fermi levels, being "rocked" back and forth between the two EC layers.

Of all the Type 2 EC materials known to the author, polycrystalline (pc) tungsten oxide (nominally $\mathrm{WO}_{3}$ ) appears to be unique as regards its being able to attain a substantial reflectivity modulation [e.g., $\mathrm{R}(\lambda \approx 2.5 \mu \mathrm{m}) \approx 95 \%$ for crystalline $\mathrm{Na}_{0.9} \mathrm{WO}_{3}$ and $\mathrm{R}(\lambda \approx 2.5 \mu \mathrm{m}) \geq 80 \%$ for thin film $\mathrm{pc}-\mathrm{Li}_{0.5} \mathrm{WO}_{3}$, as shown in Fig. 5]. This apparent uniqueness is likely associated with the $\mathrm{WO}_{3}$ conduction band, which has a relatively low effective mass and a low density of states in the vicinity of the bottom of its conduction band [5]. On the basis of band structure calculations, $\mathrm{LiCoO} 2$ was chosen to complement $\mathrm{WO}_{3}$; and among the $\mathrm{LiMO}_{2}$ compounds $(\mathrm{M}=\mathrm{a}$ transition metal atom, such as $\mathrm{Ti}, \mathrm{Cr}, \mathrm{Ni}$ ), $\mathrm{LiCoO}_{2}$, like $\mathrm{WO}_{3}$, appears to be a relatively unique choice for a complement to $\mathrm{WO}_{3}$. This, too, can be attributed to its band structure [5].

\section{Part 2}

\section{Introduction}

This is a review of some of the technologies and processes which are applicable to producing EC windows for buildings and vehicles, with a particular focus on the Tufts EC window (ECW) technology. At the end is an Executive Summary.

\section{Requirements of Building and Vehicle EC Windows}

It should be noted that, because building and vehicle EC windows will be exposed to many thousands of hours $(\approx 4000$ hours/year $)$ of solar radiation, they need to be optically and mechanically stable to such an exposure. In particular, there should be little, if any, persistent discoloration or translucence (optical scattering or cloudiness) caused by exposure to solar radiation; and there should be no window cracking, especially caused by excess heat-induced strain.

Additionally, for retrofit (after-market) building and vehicle window applications, for practical reasons, it is highly desirable that a flexible substrate (plastic) be used.

As discussed earlier, and in accompanying reprints, for building and vehicle windows, it is highly desirable to use spectrally-selective transmission modulation, and it is also highly 
desirable to minimize heat-induced strain; therefore, reflectivity modulation is the preferred mode of operation.

To obtain efficient high transmissivity modulation over the solar spectrum, it is advisable that $\mathrm{EC}_{1}$ and $\mathrm{EC}_{2}$ be complementary (one n-type, one p-type) wide bandgap semiconductors in addition to them being mixed electron and ion conductors. When electrons and accompanying charge-compensating ions are extracted from one EC layer and inserted into the other EC layer, the two layers will synchronously "color" or "bleach" because of the synchronous change in population of the electrons (and/or holes) in the EC layers. If the electrons are relatively free, this leads to a dispersive, (i.e., color-dependent) reflectivity modulation. However, only one of the two EC layers needs to be capable of providing a relatively high reflectivity modulation, namely the EC layer that will face the sun. (Note that reflectivity is not reciprocal if there are absorbing layers.)

Another optical requirement is that there be a relatively large depth of transmissivity modulation, and especially a relatively high optical density for the window in its low

transmission, ("colored") state. Satisfying this requirement will provide for night-time privacy in building and daytime security for parked vehicles.

Switching large area windows $\left(\approx 1\right.$ meter $\left.^{2}\right)$ in "reasonable" times $(<3$ minutes for buildings and $<20$ seconds for vehicles), will very likely require relatively high voltages (probably $>5$ Volts). This translates into requiring that the electrolyte layer be stable to such voltages.

The switching time requirement also puts constraints on the ionic conductivity of the electrolyte (IC) layer and on the electronic conductivity of the TC layers.

\section{Choice of Materials}

Q4 Which materials should be used for the electrolyte (IC) layer?

A4 The first decision that needed to be made was the choice of charge compensating ion $-\mathrm{H}^{+}$or $\mathrm{Li}^{+}$? Since presently there are no known room temperature electrolytes that do not require water for proton $\left(\mathrm{H}^{+}\right)$conduction, there are at least two reasons against $\mathrm{H}^{+}$: (i) avoid water sealing and incorporation difficulties; and (ii) avoid mechanical damage and irreversible loss of protons associated with gas release from electrolysis which would occur for the high overpotentials likely to be needed to obtain reasonably short switching times for large area windows. By comparison, large overpotentials can be applied to solid inorganic lithium electrolytes without irreversible damaging effects, and sealing against loss of $\mathrm{Li}^{+}$ions was not viewed as a difficult problem (and this has been experimentally verified). Thus, the first decision was to pursue $\mathrm{Li}^{+}$electrolytes.

Secondly, to obtain a durable window, an inorganic electrolyte was chosen. Highly conducting organic (polymer) electrolytes are inherently weakly bonded and therefore were expected (and have proven) to be unstable to exposure to solar radiation (usually optical degradation is readily observed in less than two weeks of solar radiation.

Another problem usually associated with polymer electrolytes is their susceptibility to the formation of highly resistive layers at the interfaces of such electrolytes with the EC layers, 
which is due to oxidation occurring at voltages $\geq 5$ Volts; and this is the expected range of applied voltages needed to switch relatively large area building and vehicle windows in reasonable times (probably $\leq 3$ minutes for buildings, and $\leq 20$ seconds for vehicles).

The following four solid inorganic lithium electrolytes are among those that have been considered at Tufts: lithium aluminum fluoride (LAF), lithium borate (LBO), lithium niobate (LNO), and lithium phosphorus oxynitride (Lipon). All electrolytes have been reported to have room temperature lithium ion conductivities $>10^{-6} \mathrm{~S} / \mathrm{cm}$ either in bulk form and/or in thin film form.

LAF suffers from three problems - (i) low crystallization temperature (which can lead to cracking and shorts upon heating and cooling); and (ii) it is readily hydrated (which can lead to manufacturing difficulties); and (iii) it is a fluoride with potential attendant safety problems especially upon hydration.

LBO also suffers from readily being hydrated which makes it a difficult material to use in a manufacturing environment.

LNO films suffer from one problem: unless stoichiometric they act like a mixture of $\mathrm{Li}_{2} \mathrm{O}$ and $\mathrm{Nb}_{2} \mathrm{O}_{5}$, with the latter being a mixed ion-electron conductor and they thereby require electron potential energy barriers to prevent electron injection or extraction. Also, the room temperature lithium ion conductivity of LNO films rf sputter-deposited at Tufts is approximately $0.5 \times 10^{-7}$ $\mathrm{S} / \mathrm{cm}$. However, this conductivity is sufficiently high enough to allow small area cells $\left(2 \mathrm{~cm}^{2}\right)$ employing approximately $0.5 \mu \mathrm{m}$ thick LNO films to be switched in times as short as 5 to 10 seconds at room temperature. Furthermore, EC window cells employing LNO have successfully undergone $>20,000$ deep coloring and bleaching cycles, without the appearance of any degradation.

Lipon films that are deposited either by electron beam evaporation or by if magnetron sputtering have been employed successfully in relatively high voltage $(>4 \mathrm{~V})$ rechargeable batteries, and exhibit room temperature lithium ion conductivities from $2 \times 10^{-7}$ to $2 \times 10^{-6} \mathrm{~S} / \mathrm{cm}$. Rechargeable battery cells $\left(1 \mathrm{~cm}^{2}\right)$ employing Lipon electrolytes have likewise successfully undergone thousands of deep charging and discharging cycles with little evidence of degradation.

A major issue that needs to be addressed is that of devising practical deposition process for one or more of these electrolytes that will provide for high throughput (rapidly produce large areas free of electronic shorts or relatively low breakdown voltages). Currently, the most attractive process appears to be reactive electron beam evaporation, but further research and development is needed. However, very recently a proprietary process has been developed at Tufts that allows one to rapidly deposit fully dense Lipon films (e.g., deposition rates exceeding $5 \AA / s$ have been achieved. and it can be extended to $>25 \AA / s$ ). It is anticipated that with further research Lipon deposited by the Tufts proprietary technique will prove to be a preferred production method, and should lead to low cost ECW's.

In summary, this author is unaware of any reports in which EC windows that employ polymer electrolytes have successfully withstood solar exposure; rather, this author has seen and has been informed that EC window prototypes employing polymer electrolytes of at least two manufacturers (Saint Gobain - France, and Asahi Glass - Japan) seriously degraded after relatively short solar exposures ( $<250$ hours). Additionally, polymer electrolytes generally have other inherent problems - low density + high elasticity $\Rightarrow>$ requirement that the electrolyte be relatively thick to prevent shorting of large area sandwich windows. This translates into 
thicknesses probably $\geq 100 \mu \mathrm{m}$, which indicates that any gains in ion conductivity over inorganics is canceled as far as ion conductance is concerned (since $<1 \mu \mathrm{m}$ thick inorganic electrolyte films having breakdown voltages $>10 \mathrm{~V}$ can be fabricated quite readily). Also, there have been reports of inorganic electrolytes having room temperature lithium ion conductivities, $\sigma_{\mathrm{L} . \mathrm{i}}(\mathrm{RT})>10^{-5} \mathrm{~S} / \mathrm{cm}$ (sulfides), and there are reports of the deposition of moisture-resistive inorganic electrolyte films with $\sigma_{\mathrm{Li}}(\mathrm{RT}) \geq 10^{-6} \mathrm{~S} / \mathrm{cm}$ (e.g., Lipon). (Lipon films deposited at Tufts by the proprietary technique have $\sigma_{\mathrm{Li}}(\mathrm{RT}) \approx 10^{-6} \mathrm{~S} / \mathrm{cm}$.)

Q6 Which electrochromic materials should be used?

A6 Because of the spectrally-selective reflectivity modulation requirement for building and vehicles windows, at least one of the EC layers should be capable of a high degree of reflectivity modulation. Unfortunately, there appears to be but one material, polycrystalline (pc) tungsten oxide (nominally $\mathrm{WO}_{3}$ ), the classical EC material. As mentioned earlier, this most likely is due to its relatively low mass conduction band, arising primarily from the $\mathrm{W} 5 \mathrm{~d}$ electrons. Thus, this is the primary candidate for $\mathrm{EC}_{1}$. It should be noted that to achieve high reflectivity modulation in any material by using free carriers requires that there be a high degree of compositional and structural order; otherwise, the optical frequency scattering will severely restrict the maximum reflectivity and will result in an undesirable high average optical absorption.

Research at Tufts has led to developing an oxygen ion assisted deposition (IAD) technique that enables one to deposit $\mathrm{pc}-\mathrm{WO}_{3}$ on to ambient temperature substrates, including on to a plastic (e.g., Mylar) substrate; and it exhibits good reflectivity modulation [4]. The technique is patented and could probably be readily used for rapid depositions by using a high current density gridless ion gun for oxygen ions of controlled energy and current density, together with a swept high current density electron beam evaporation source for the $\mathrm{WO}_{3}$.

With $\mathrm{EC}_{1}=$ (n-type) $\mathrm{pc}-\mathrm{WO}_{3}$, a p-type, complementary $\mathrm{EC}$ layer is needed for $\mathrm{EC}_{2}$. Although there are several possibilities, especially among the $\mathrm{Li}_{\mathrm{x}} \mathrm{M}_{\mathrm{y}} \mathrm{O}_{\mathrm{z}}$ compounds $(\mathrm{M}=$ transition metals, e.g., $\mathrm{Co}, \mathrm{Ni}, \mathrm{Ti}, \mathrm{V}, \mathrm{Cr}$, etc.), once again there appears to be a relatively unique choice namely $\mathrm{LiCoO}_{2}$, that has a band structure which provides for its being transparent in its chemically reduced (fully lithiated) state and colors as lithium and electrons are removed. Furthermore, research done at Tufts indicates that thin films of $\mathrm{LiCoO}_{2}$ deposited by rf sputtering can have close to the requisite optical modulation properties. (Please note curve b1 of Fig. 2 of [7], a reprint of which accompanies this report; and the figure is reproduced as Fig. 4 in this report.) One difficulty which arises at the $\left[\mathrm{EC}_{2}=\mathrm{LiCoO} / \mathrm{TC}_{2}=\mathrm{In}_{2} \mathrm{O}_{3}\right]$ heterojunction is that this heterojunction generally prevents easy electron transport in one or both directions (i.e., it acts like a nonohmic contact). This can cause difficulties in switching windows uniformly with moderately low voltages. Recently, however, a proprietary process has been developed at Tufts which appears to have solved the problem.

\section{Properties of $\mathrm{pc}-\mathrm{WO}_{3}$ and $\mathrm{LiCoO}_{2}$}

Single layers of $\mathrm{pc}-\mathrm{WO}_{3}, 150$ to $200 \mathrm{~nm}$ thick, and colored by plasma insertion of lithium, demonstrate a near infrared reflectivity $\geq 80 \%$ (Fig. 5); and until recently, it has been difficult 


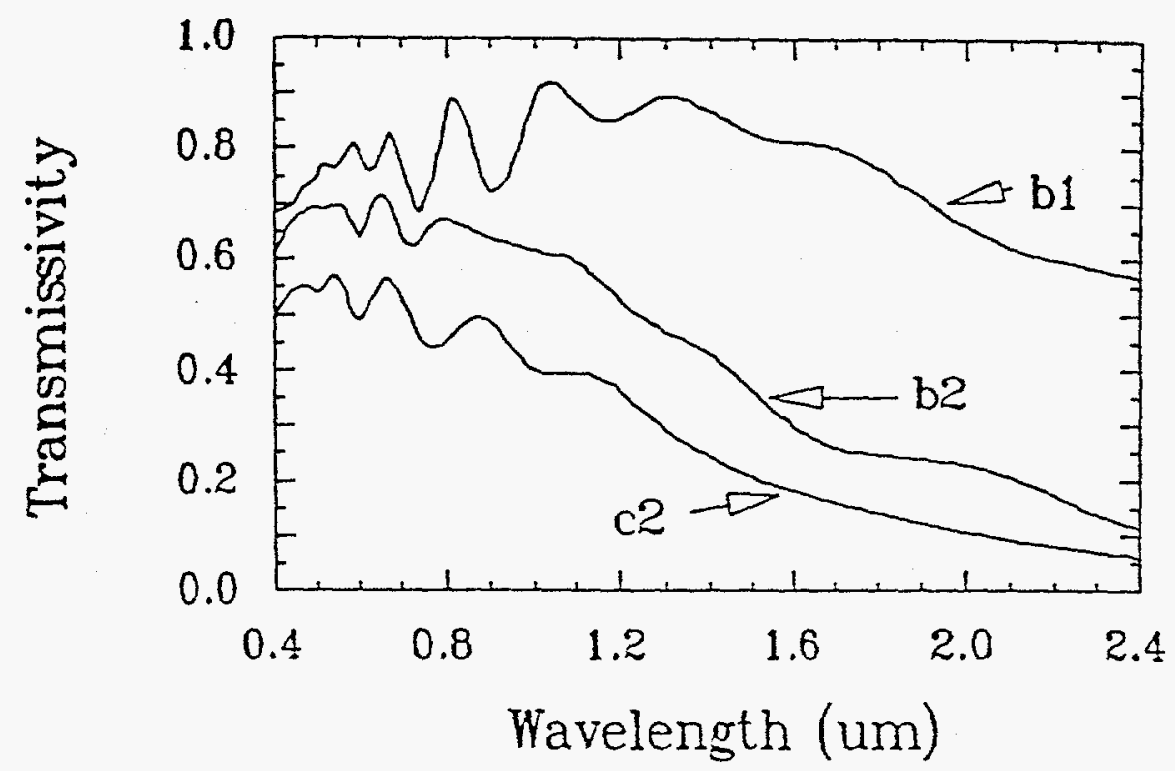

Fig. 4 Transmissivity modulation for $2 \mathrm{~cm}^{2}$ electrochromic window cell, $\mathrm{H} 193 \mathrm{f}$, [(glass = substrate $) /\left(200 \mathrm{~nm}\right.$ ITO $\left.=\mathrm{TC}_{1}\right) /(90 \mathrm{~nm}$ $\left.\mathrm{WO}_{3}=\mathrm{EC}_{1}\right) /\left(350 \mathrm{~nm} \mathrm{LiNbO}_{3}=\mathrm{IC}\right) /\left(50 \mathrm{~nm} \mathrm{LiCoO} 2=\mathrm{EC}_{2}\right) /(100 \mathrm{~nm}$ $\left.\mathrm{In}_{2} \mathrm{O}_{3}=\mathrm{TC}_{2}\right)$ ]; (ITO = indium tin oxide). This cell had no $\mathrm{Li}^{+}$ blocking layer between $\mathrm{TC}_{1}$ and $\mathrm{EC}_{1} \cdot \mathrm{bl}=$ initial bleached state; $\mathrm{b} 2$ $=$ bleached state after cycling 9,000 times; $c 2=$ colored state after cycling 9,000 times. Cycling was done at $60^{\circ} \mathrm{C}$ in an argon atmosphere. 


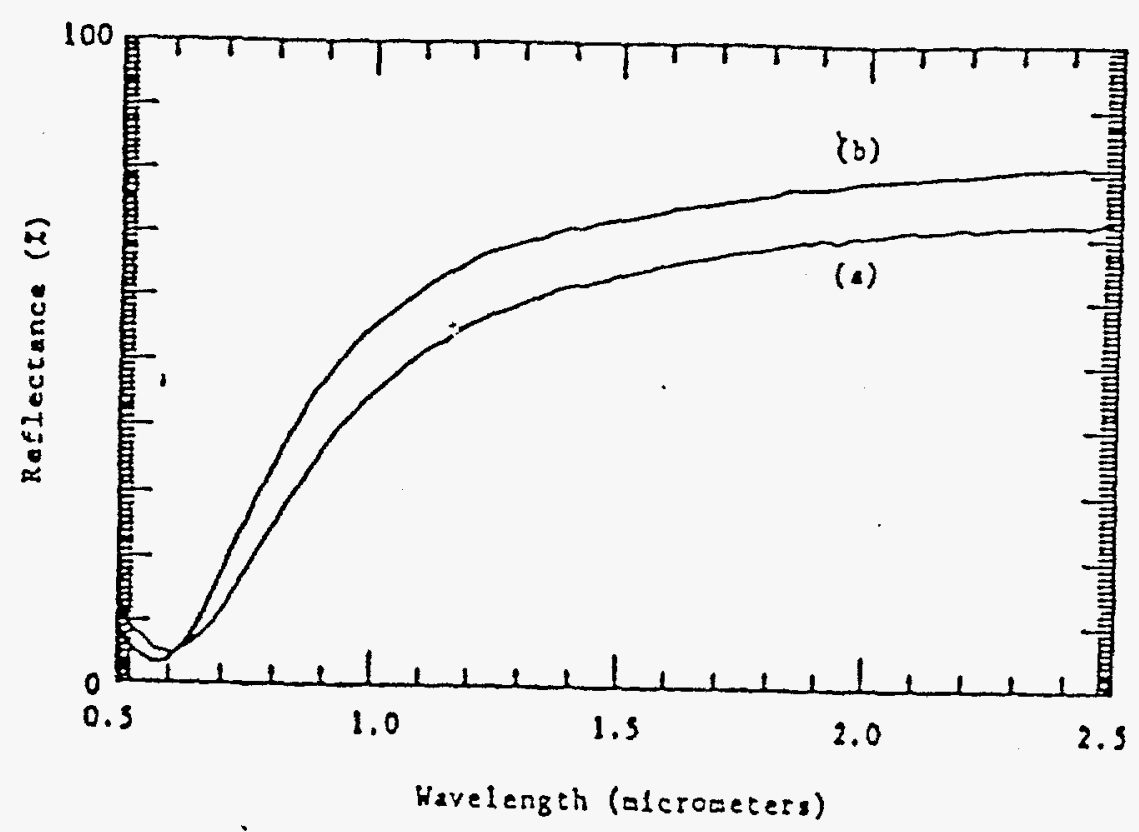

-Fig. 5 Reneclivity wavelength dependence for two polycrystalline $\mathrm{Li}_{x} \mathrm{WO}_{3}$ films. $\left[E_{p} E_{T} \mid\right.$ poirs $=(\mathrm{a})[3.43 \mathrm{eV}, 0.59 \mathrm{eV}]_{i}(\mathrm{~b})[3.50 \mathrm{eV}, 0.42 \mathrm{eV})$.

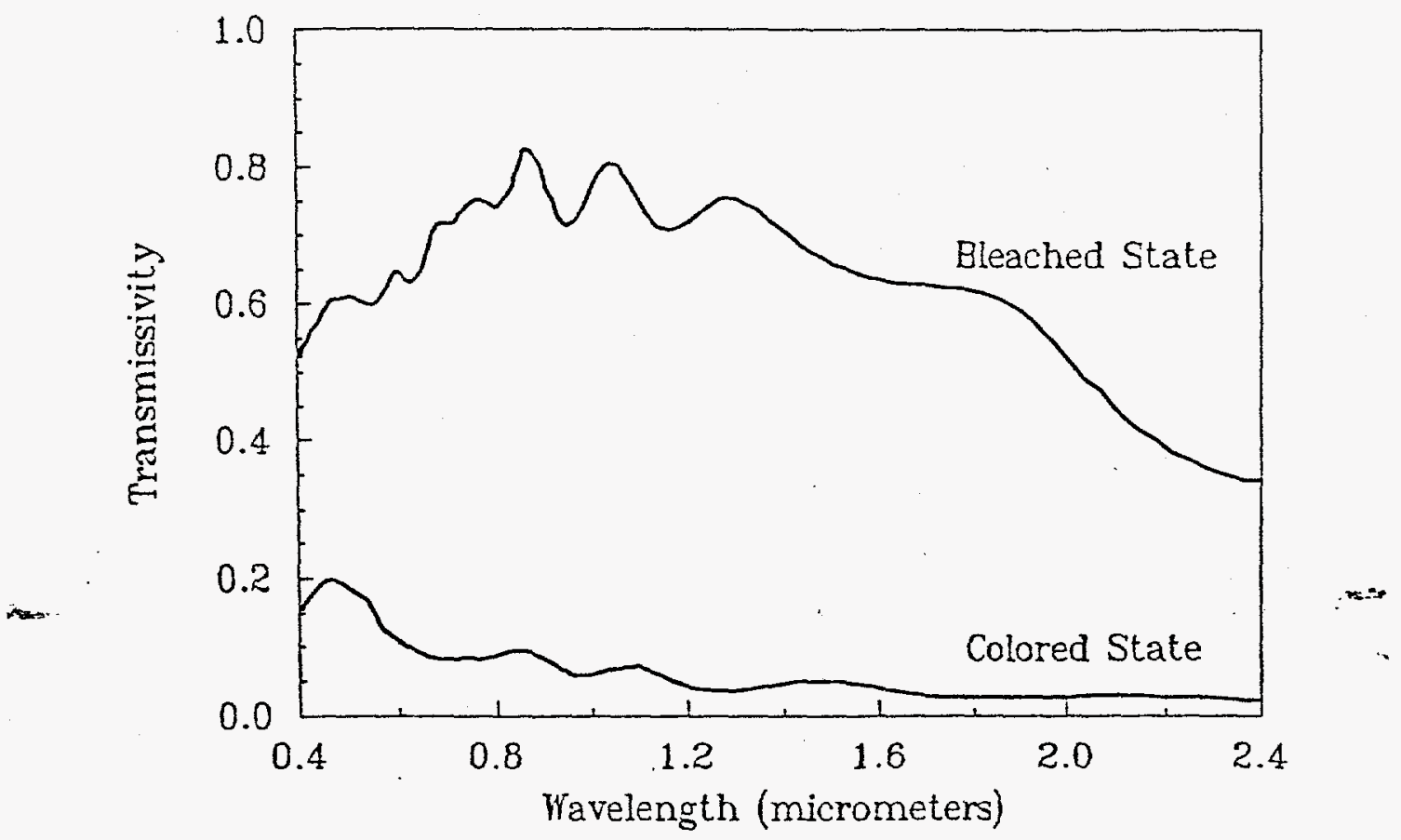

Fig. 6 Transmissivity modulation for an unsealed $2 \mathrm{~cm}^{2}$ electrochromic window cell, H237b, [(glass = substrate $) /(200 \mathrm{~nm}$ ITO $\left.=\mathrm{TC}_{1}\right) /\left(100 \mathrm{~nm} \mathrm{WO}_{3}=\mathrm{EC}_{1}\right) /\left(450 \mathrm{~nm} \mathrm{LiNbO}_{3}=\mathrm{IC}\right) /(50 \mathrm{~nm}$ $\left.\left.\mathrm{LiCOO}_{2}=\mathrm{EC}_{2}\right) /\left(100 \mathrm{~nm} \mathrm{In}_{2} \mathrm{O}_{3}=\mathrm{TC}_{2}\right)\right]$; (ITO = indium tin oxide $)$. This cell had an n-type $\mathrm{Li}^{+}$blocking layer (approximately $20 \mathrm{~nm}$ thickness) between $\mathrm{TC}_{1}$ and $\mathrm{EC}_{1}$. 
to attain window cells which exhibit colored state near infrared (wavelengths $>700 \mathrm{~nm}$ ) reflectivities greater than $40 \%$. However, by using newly developed proprietary processes, Tufts ECW's have exhibited colored-state near infrared reflectivities $>60 \%$, and with further research it is anticipated that ECW's should be capable of exhibiting reflectivities closely approaching $80 \%$.

Band structure calculations indicate that $\mathrm{LiCoO}_{2}$ should have a band gap $\approx 3 \mathrm{eV}$, which indicates that bleached (fully lithiated) $\mathrm{LiCoO}_{2}$ should be highly transparent for wavelengths $\geq$ $400 \mathrm{~nm}$. These calculations have been approximately confirmed - we have observed for ECW's incorporating $\approx 100 \mathrm{~nm}$ thick $\mathrm{LiCOO}_{2}$ films that have been properly deposited, bleached-state transmissivities $\geq 70 \%$ for wavelengths $>450 \mathrm{~nm}$.

Q7 Which materials should be used for the transparent conductors?

A7 Either indium tin oxide (ITO) or chemically reduced (controlled oxygen deficiency) indium oxide (nominally $\mathrm{In}_{2} \mathrm{O}_{3}$ ) films can be used for the TC layers. The advantage of using $\mathrm{In}_{2} \mathrm{O}_{3}$ is that for the same carrier concentration, a higher mobility film can be obtained than for ITO with a consequent higher conductivity; or for the same conductivity, a lower plasma frequency (or wider transmission bandwidth) can be obtained for $\operatorname{In}_{2} \mathrm{O}_{3}$ than for ITO. A proprietary production-worthy technique has been developed at Tuft which allows one to obtain high conductivity, low plasma frequency $\operatorname{In}_{2} \mathrm{O}_{3}$ films, and these films in conjunction with another proprietary practical technique should allow one to relatively rapidly switch large area ECW's without the necessity of having excessively high voltages (which for proton-based, or water-based windows is only approximately 1.5 to 2 volts!) and metallic conductivities which are essentially unattainable by transparent conducting metal oxides. It should also be noted that to prevent changing the oxidation state of the top transparent conductor $\left(\mathrm{TC}_{2}\right)$ and, equally important, to prevent loss of lithium ions at the top surface due to air reactions, it is advisable to seal the top layer; and this has been successfully done by a Tufts proprietary production-worthy process

Q8 What limits the colored state optical density [O.D. $=\log _{10}(1 / \mathrm{T}), \mathrm{T}=$ transmissivity] of an ECW?

A8 The colored state O.D. of a window is determined by the thickness and degree of chemical reduction (molar concentration of inserted $\mathrm{Li}^{+}$) for the cathodically-coloring $\mathrm{n}$-type $\mathrm{EC}$ layer (such as $\mathrm{pc}-\mathrm{WO}_{3}$ ), or by the thickness and degree of chemical oxidation (molar concentration of extracted $\mathrm{Li}^{+}$) for the anodically-coloring p-type EC layer (such as $\mathrm{LiCoO}_{2}$ ). There are practical as well as theoretical limits to these parameters. For example, the maximum change in molar concentration, $\left\{\Delta\left[\mathrm{Li}^{+}\right] /\left[\mathrm{WO}_{3}\right]\right\}_{\max } \approx 0.7$; and the maximum change in molar concentration, $\left\{\Delta\left[\mathrm{Li}^{+}\right] /\left[\mathrm{LiCoO}_{2}\right]\right\}_{\max } \approx 0.9$; and the thicknesses of the two EC layers are limited by the minimum acceptable transparent state transmissivity. It is estimated that probably the maximum practically attainable average colored state O.D. $\approx 2$, averaged over the visible spectrum (corresponding to a minimum average visible state transmissivity of $\approx 1 \%$ ). This would be for a $\mathrm{WO}_{3}$ layer of approximately $200 \mathrm{~nm}$ thickness and a $\mathrm{LiCoO}_{2}$ layer of approximately 150 $\mathrm{nm}$ thickness. 
What limits the ECW maximum colored state reflectivity?

A9 The ECW maximum colored state reflectivity is ultimately limited by the maximum allowable thickness and $\left\{\Delta\left[\mathrm{Li}^{+}\right] /\left[\mathrm{WO}_{3}\right]\right\}_{\max } \approx 0.7$, and both are determined to a large extent by the internal stress and its change upon lithium insertion or extraction for the $\mathrm{WO}_{3}$ film which, in turn, is highly dependent upon the deposition process. The reflectivity is practically limited by the optical absorption coefficient of the counterelectrode, $\mathrm{EC}_{2}$. For example, structurally ordered and stoichiometric $\mathrm{LiCoO}_{2}$, an attractive complement to $\mathrm{WO}_{3}$, should have a high transmissivity (> 70\%) in the 400 to $500 \mathrm{~nm}$ wavelength range; however, $\mathrm{LiCoO}_{2}$ films deposited by a sputtering process or even by a CVD process, usually end up with structural disorder and are nonstoichiometric, with consequent transmissivity reduction $(\mathrm{T}<65 \%)$ in the 400 to $500 \mathrm{~nm}$ wavelength range.

Q10 What are currently attainable ECW characteristics?

A10 Shown in Fig. 5 is a typical colored state reflectivity for a single layer of pc- $\mathrm{WO}_{3}$, and shown in Fig. 6 (Fig. 3 of [5], accompanying this report) are the optical modulation properties for a typical Tufts ECW. Switching times as short as 5 seconds can be obtained for $2 \mathrm{~cm}^{2}$ cells, for switching voltages $\approx+/-2$ to $3 \mathrm{~V}$. Such windows are robust, having been cycled for more than 20,000 times without any signs of degradation. Shown in Fig. 7 are the colored state reflectivity, and the bleached state transmissivity and reflectivity characteristics for a recently fabricated electrochromic window cell; and these indicate that one can fabricate ECW's which have low absorption modulation but have more than $\mathbf{5 0 \%}$ reflection modulation.

Q11 What materials and deposition process(es) should be used for producing ECW's?

A11 For reasons largely stated above and articulated in our publications, our materials recommendations are as summarized in Table 1 .

\section{Table 1 - Summary of Recommended Materials for Scaled- Up Windows.}

1. $\mathrm{TC}_{1}=\mathrm{In}_{2} \mathrm{O}_{3}$.

2. Li-barrier layer $=$ Tufts developed thin film.

3. $\mathrm{EC}_{1}=\mathrm{pc}-\mathrm{WO}_{3}$.

4. $\quad$ IC $=$ inorganic electrolyte $=$ Lipon.

5. $\quad \mathrm{EC}_{2}=\mathrm{LiCoO}_{2}$.

6. Ohmic contact at $\mathrm{EC}_{2} / \mathrm{TC}_{2}$ interface $=$ Tufts developed thin film.

7. $\mathrm{TC}_{2}=$ same as $\mathrm{TC}_{1}$.

8. Sealant layer $=$ Tufts developed thin film.

As for deposition processes, we believe that the issue has not yet been resolved; however, prior to even pilot manufacture of ECW's, based on studies at Tufts, one may conclude that 
further basic research is needed to establish a better understand the relationships between the deposition parameters of any particular deposition process and the resulting nanostructure (and microstructure) and thermomechanical properties. That is, more basic research is needed that closely couples experiment and modelling. Unless the deposition parameters/nanostructure/thermomechanical properties relationships are reasonably well understood, the consequences can be dire for ECW technology, no less the DOE ECW program. This is because, in the present economic climate, industry has been very reluctant to invest in such basic research, but without doing so, costly errors are very likely to be made. Therefore, since it is government's rightful role to invest in the discovery of new knowledge and its dissemination (largely via the education of its citizens), it is strongly recommended that public monies be so invested - i.e., by funding a research program of this nature at one or more universities. An example of the value of such research is summarized in Appendix I which lists some of the major accomplishments that resulted from the DOE-sponsored ECW research program at Tufts University. Also, as listed in Appendix II, this information has been made publicly available via more than three dozen publications (in addition to a like number of invited public technical lectures. 


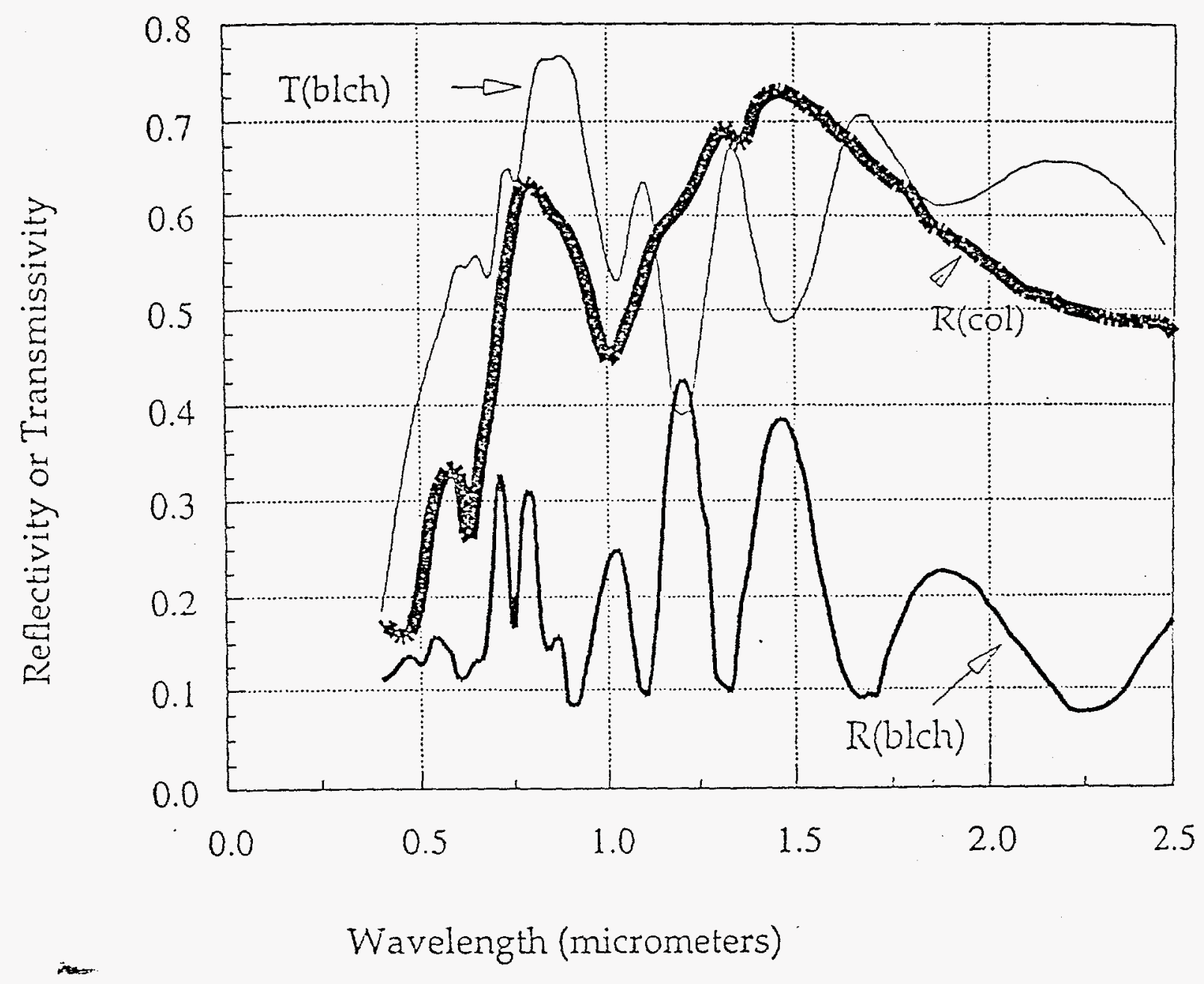

Fig. 7 Colored state reflectivity (upper dark curve) and bleached state reflectivity (lower dark curve) and bleached state transmissivity (upper light curve) for sample H798 ([glass substrate/TTO/Li-block/ WO $/$ Lipon/LiCoO$/$ sealant]). 


\section{References}

1. e.g., G.Fowles, "introduction to Modern Optics," 2nd edition, Holt, Rinehart, and Winston, NY (1975); also in Dover edition.

2. R.Siegel and J.R.Howell, "Thermal Radiation Heat Transfer," Vol 1, NASA SP-164, Library of Congress Catalog Card Number 67-62877 (1968).

3. F.Wooten, "Optical Properties of Solids," Academic Press, NY (1972).

4. T.E.Haas and R.B.Goldner,"Fundamentals of Electrochromism in Metal Oxide Bronzes," Chapter of book, "Large Area Chromogenics," edited by C.M.Lampert and C.G.Granqvist, Vol.IS 4, 170, SPIE Optical Engineering Press, Bellingham, WA (1990).

5. R.B.Goldner, et al., "d-electron and two active thin film devices for achieving a solar energy economy," Solar Energy Materials and Solar Cells, 32, 421 (1994).

6. F.O.Arntz, et al., "near infrared reflectance modulation with electrochromic crystalline $\mathrm{WO}_{3}$ films deposited on ambient temperature glass substrates by an oxygen ion-assisted technique," J.Appl.Phys.67, 3177 (1990).

7. R.B.Goldner, "Some lessons learned from research on a thin film electrochromic window," Solid State Ionics 70/71, 613 (1994).

8. Boston Globe article 9 April 1996. 
APPENDIX I 


\section{Some significant accomplishments obtained at Tufts EOTC (References refer to Tufts publications)}

1. Identified the importance of using spectrally-selective reflection modulation for practical building and vehicle electrochromic windows $[1,3]$.

2. Demonstrated the applicability of the Drude free electron model for understanding reflection and absorption modulation in polycrystalline films of $\mathrm{WO}_{3}[1,2,3]$.

3. Demonstrated high reflection modulation in polycrystalline films of $\mathrm{WO}_{3}[1,11,17]$.

4. Obtained a patent for reflectivity modulation electrochromic windows [19].

5. Demonstrated high near infrared reflection modulation $(>60 \%)$ in a complete electrochromic window cell [cf. Fig. 7 of this report].

6. Identified by modelling and experiments the major scattering mechanisms in polycrystalline films of $\mathrm{WO}_{3}$ $[4,6]$.

7. Obtained direct experimental proof of the applicability of the rocking-chair model for lithium based electrochromic windows [29].

8. Determined that $\mathrm{In}_{2} \mathrm{O}_{3}$, ITO, and $\mathrm{SnO}_{2}$ are insertion materials, and that the latter two insert less reversibly than does $\operatorname{In}_{2} \mathrm{O}_{3}$, which itself has a relatively low lithium diffusion coefficient; and therefore identified the need to develop a lithium blocking layer between at least $\mathrm{WO}_{3}$ and the bottom transparent conducting metal oxide layer $[5,21,30]$.

9. Successfully developed a proprietary lithium ion barrier layer $[29,30]$.

10. Theoretically predicted and experimentally proved that $\mathrm{LiCOO}_{2}$ is a good complementary electrochromic layer to $\mathrm{WO}_{3}[26]$.

11. Developed rocking-chair electrochromic window cells that cycled reversibly for $>20,000$ cycles (at $70^{\circ} \mathrm{C}$ ) [30].

12. Developed a proprietary high deposition rate process for depositing Lipon which has a room temperature lithium ion conductivity approximately $10^{-6} \mathrm{~S} / \mathrm{cm}$, has bulk mass density, is not hygroscopic, and is a true lithium ion conductor (1996).

13. Developed a proprietary ohmic contact at the heterojunction between $\mathrm{LiCoO}_{2}$ and $\mathrm{In}_{2} \mathrm{O}_{3}$

14. Identified the importance of stress and stress changes as regards yields of functioning electrochromic cells, and as regards their cycle life (1995).

15. Developed a practical stress measuring apparatus that could be used on the bench and/or in a vacuum system (1994).

16. Developed a low $\mathrm{E}_{\Gamma}$ and high electron mobility $\mathrm{In}_{2} \mathrm{O}_{3}$ layer (1995).

17. Developed a proprietary process that would allow one to rapidly switch large area electrochromic windows with modest voltages (1985).

18. Developed a simple in-situ, and "on the fly", technique for measuring lithium ion chemical diffusion constants [38].

19. Identified that the band gap in $\mathrm{WO}_{3}$ decreases as the concentration of inserted lithium increases [22].

20. Determined that for $\mathrm{WO}_{3}, \mathrm{E}_{\Gamma}$ increases as concentration of inserted lithium ions increases, and modelled the same $[6,11,16]$.

21. Demonstrated a practical technique for rapidly depositing reflective, polycrystalline $\mathrm{WO}_{3}$ on to an ambient temperature substrate (including plastic) $[20,24]$.

22. Developed a low cost, computer controlled, multi-channel station which incorporates optical end point switching for life cycling electrochromic window cells (1994).

23. Developed a low cost sealant process for electrochromic window cells (1994).

24. Pointed out, based on band structure modelling, that $\mathrm{WO}_{3}$ and $\mathrm{LiCoO}_{2}$ are probably optimum choices for reflection modulation electrochromic windows [33,35]. 
APPENDIX II 
Published papers related to DOE-sponsored electrochromic windows research at Tufts University

1) "High near infrared reflectivity modulation with polycrystalline electrochromic $\mathrm{WO}_{3}$ films,"Appl.Phys. Lett.43, 1093(1983).

2) "Ellipsometric measurements as direct evidence of the Drude model for polycrystalline electrochromic $\mathrm{WO}_{3}$ films," J.Electrochem.Soc.131, 857(1984).

3) "Electrochromic materials for controlled radiant energy transfer in buildings,"(special invited paper), Proc.SPIE 428, 38(1983); and Solar Energy Materials 12, 413(1984).

4) "Optical frequencies free electron scattering studies on electrochromic materials for variable reflectivity windows," Proc.SPIE 502, 54 (1984); \& Solar Energy Mat'ls 12, 403(1985).

5) "Electrochromic behavior in ITO and related oxides, "Appl.Opt. 24, 2283(1985).

6) "Further evidence for free electron scattering as dominating the behavior of electrochromic polycrystalline $\mathrm{WO}_{3}$ films," Appl.Phys.Lett. 47, 536(1985).

7) "Smart Windows"-testimony at hearing of U.S. House of Representatives Subcommittee on Energy and Power, Boston,MA. (21 Oct 1985).

8) "Recent research on electrochromic windows,"Proc.SPIE 562, 32(1985).

9) "Thin $\mathrm{WO}_{3}$ films for electrochromic windows,"Proc.SPIE 692, 39(1986).

10) "Status of research on electrochromic windows," Proc.Nat'l.Res.Coord.Comm.on Building Thermal Envelope Materials," Wash., DC (2 June 1986).

11) "Improved colored state reflectivity in lithiated $\mathrm{WO}_{3}$ films, Proc.SPIE $\underline{823}$, 101(1987).

12) "Sputter deposited thin films of $\mathrm{LiNbO}_{3}$ and $\mathrm{LiTaO}_{3}$ for the ion conducting layer of smart windows," Proc.SPIE $\underline{823}, 81 \cdot(1987)$.

13) "Thin film solid state ionic materials for electrochromic smart window glass," Solid State Ionics $\underline{28}$, 1715(1988).

14) "Completely solid lithiated smart windows," Solar Energy Mat'ls $\underline{19}$, 17(1989).

15) "Fundamentals of electrochromism in metal oxide bronzes," chapter of book, "Large Area

Chromogenics," SPIE Press, Bellingham, WA. (1990).

16) "Lithium cobalt oxide thin film and its electrochromism," Proc.of Electrochem.Soc.Conf.on Electrochromic Materials, 90-2, 80 (1989).

17) "Reflectance modulation with electrochromic $\mathrm{Li}_{x} \mathrm{WO}_{3}$ Films," Proc.of Electrochem.Soc.Conf.on

Electrochromic Materials, 90-2, 14 (1989).

18) "Thin film ion conducting coating," U.S.Patent 4,832,463 (23 May 1989).

19) "Light modulating device," U.S.Patent 4,889,414 (26 Dec. 1989).

20) "Electrochromic crystalline $\mathrm{WO}_{3}$ films prepared at ambient temperature by ion-assisted deposition,"

Proc.SPIE 1149, 40 (1989);\& J.Appl.Phys.67, 3177 (1990).

21) "Characterization of Indium Oxide for Use as a Counterelectrode in an Electrochromic Device,"

Proceedings of the Materials Research Society Meeting - Boston, MA (Dec. 1990).

22) "A Study of the Optical Bandgap of Lithium Tungsten Trioxide Thin Films," Proceedings of the

Materials Research Society Meeting - Boston, MA (Dec. 1990).

23) "Progress on the variable reflectivity electrochromic window," Proc.SPIE 1536-34, (July 1991).

24) "Ion-beam based deposition of coatings for electrochromic devices," U.S.Patent 5,051,274 (24Sept1991).

25) "A monolithic thin film electrochromic window," Solid State Ionics 53-56, 617 (1992).

26) "Thin films of lithium cobalt oxide," Solid State Ionics 58, 115 (1992).

27) "One-dimensional diffusion into a multilayer structure: An exact solution... "J.App.Phys.72,4674 (1992).

28) "Method for manufacturing solid state ionic devices," U.S.Patent 5,171,413 (15 Dec. 1992).

29) "Nuclear reaction analysis profiling as direct evidence for lithium ion mass transport in thin film 'rocking-chair' structures," Appl.Phys.Lett. 62, 1699 (1993).

30) "Some lessons learned from research on a thin film electrochromic window," Sol.State Ionics 70/71, 613 (1994).

31 ) "Electrochemical, chemical, and optical characterization of electrochromic $\mathrm{Li}_{0} \mathrm{Nb}_{2} \mathrm{O}_{5}(0 \leq \delta \leq 1.5)$," Proc. Electrochem. Soc. PV 94-2, 122 (1994).

32) "A robust completely inorganic electrochromic window for building applications," Proc. Electrochem. Soc., 
PV94-2, 237 (1994).

33) "d electrons and two active thin film devices for achieving a solar energy economy,"(invited paper) Solar Energy Materials and Solar Cells 32, 421 (1994).

34) "Properties of a carbon negative cathode in completely inorganic thin film Li-ion batteries with a $\mathrm{LiCoO}_{2}$ positive electrode," (invited paper) Mat.Res.Symp.Proc. Solid State Ionics 369, 137 (1995).

35) "Attaining a solar energy economy with active thin film structures," (invited paper) J.Vac.Sci.Tech. A13(3), 1088 (1995).

36) "Development of a thin film $\mathrm{Li}_{1-y} \mathrm{CoO}_{2}$ rocking-chair battery," (invited paper) Electrochemical Society Meeting, Chicago (8-13 Oct 1995); and to be published in Proc.Electrochem.Soc. (1996).

37) "Thin films of $\mathrm{In}_{2} \mathrm{O}_{3}$ for plasma filtering," submitted for publication (1996).

38) "A transient method to measure diffusion coefficients in thin film electrodes - results for $\mathrm{LiCoO}_{2}$ and C films," J.Electrochem.Soc. (June 1996). 
APPENDIX III 
Optics and Materials Research for Controlled Radiant Energy Transfer in Buildings

Table of Contents

EXECUTIVE SUMMARY $\ldots \ldots \ldots \ldots \ldots \ldots \ldots \ldots \ldots \ldots \ldots \ldots \ldots$

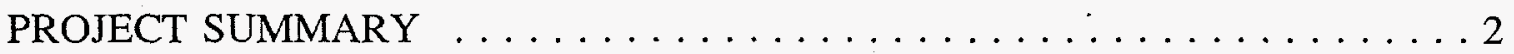

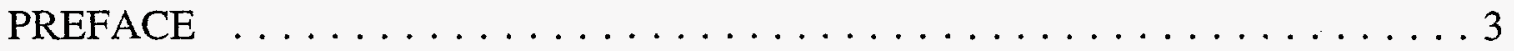

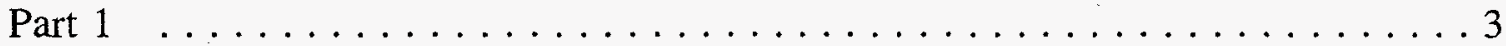

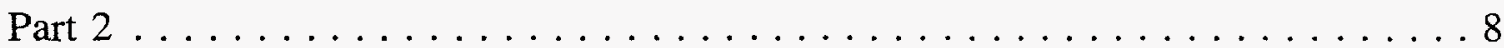

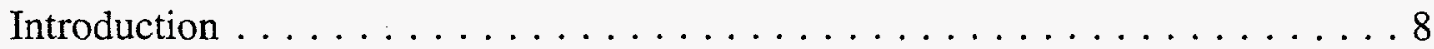

Requirements of Building and Vehicle EC Windows $\ldots \ldots \ldots \ldots \ldots \ldots$

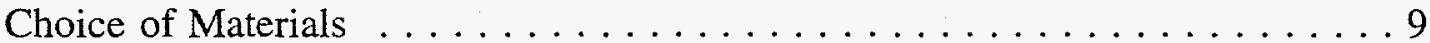

Properties of $\mathrm{pc}^{-\mathrm{WO}_{3}}$ and $\mathrm{LiCoO}_{2} \ldots \ldots \ldots \ldots \ldots \ldots \ldots \ldots \ldots$

Table 1 - Summary of Recommended Materials

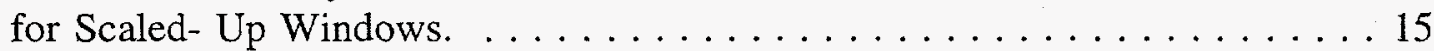

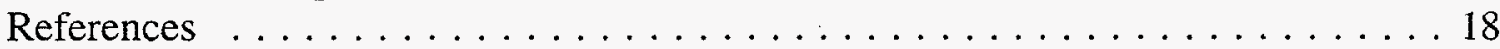

Appendix I

Some significant accomplishments obtained at Tufts EOTC ......... 19 Appendix II

Published papers related to DOE-sponsored electrochromic

windows research at Tufts University $\ldots \ldots \ldots \ldots \ldots \ldots \ldots \ldots \ldots$

Appendix III

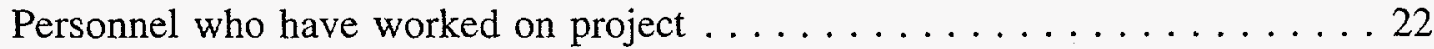

Acknowledgment ............................23

Reprints: $\longleftrightarrow$ Removed for separate

Solid State Ionics 70/71, 613-618 (1994).

J. Vac. Sci. Technol. A13(3), May/Jun 1995. 


\section{Graduate Students:}

1. Charles Amass

2. Geetha Berera

3. Richard Breitkopf

4. David Calef

5. Karen Dickson

6. Christina Garden

7. Alexandra Gerouki

8. Eric Goldner

9. Mark Goldner

10. William Henderson

11. Linas Jauniskis

12. Leo Kenney

13. Te-Yang Liu

14. Bertrand Morel

15. Peter Norton

16. George Seward

17. Simon Slaven

18. Gene Sullivan

19. Natasha Tkachenko

20. Guang Wei

21. Kwok-Keung Wong

22. Tao Wong

23. Philip Yu

\section{Staff:}

1. Floyd Arntz

2. Ralph Chapman

3. George Foley

4. Mike Frongillo

5. Ronald Goldner

6. Terry Haas

7. Te-Yang Liu

8. Howard Sample

9. Olivier Tillement

10. Shi-Jie Wen

11. Keqi Zhang

12. Peter Zerigian 